\title{
Genetic determinants of warfarin maintenance dose and time in therapeutic treatment range: a RE-LY genomics substudy
}

\begin{abstract}
Aims: We investigated associations between genetic variation in candidate genes and on a genome-wide scale with warfarin maintenance dose, time in therapeutic range (TTR), and risk of major bleeding. Materials \& methods: In total, 982 warfarintreated patients from the RE-LY trial were studied. Results: After adjusting for SNPs in VKORC1 and CYP2C9, SNPs in DDHD1 (rs17126068) and NEDD4 (rs2288344) were associated with dose. Adding these SNPs and CYP4F2 (rs2108622) to a base model increased $\mathrm{R}^{2}$ by $2.9 \%$. An SNP in ASPH ( $\left.\mathrm{rs} 4379440\right)$ was associated with TTR $(-6.8 \%$ per minor allele). VKORC1 was associated with time less than INR 2.0. VKORC1 and CYP2C9 were associated with time more than INR 3.0, but not with major bleeding. Conclusions: We identified two novel genes associated with warfarin maintenance dose and one gene associated with TTR. These genes need to be replicated in an independent cohort.
\end{abstract}

First draft submitted: 6 April 2016; Accepted for publication: 19 May 2016; Published online: 4 August 2016

Keywords: CYP2C9 • CYP4F2 • genome-wide association study $\bullet$ prediction models $\bullet$ time in therapeutic range $\bullet$ VKORC1 $\bullet$ warfarin $\bullet$ warfarin dose

\section{Introduction}

Warfarin is a commonly prescribed anticoagulant for prevention of stroke in patients with atrial fibrillation (AF). Compared to placebo, warfarin reduces the risk of stroke in AF by approximately 64\%; however, the treatment also has some shortcomings, mainly high inter-individual variation in dose needed to reach therapeutic effect, a narrow therapeutic range and increased risk of bleeding $[1,2]$. The anticoagulant effect of warfarin is measured by the international normalized ratio (INR). During the initiation phase of warfarin treatment, the dose is individualized through monitoring of the INR value and dose changes in order to reach and maintain a therapeutic range of anticoagulation, which commonly is INR 2.0-3.0 in AF [3]. There is a close relationship between INR and risk of bleeding where the risk increases at INR above 4 and rises sharply at INR above 5 [4]. Among other risk factors for bleeds during warfarin treatment are age, renal function, concomitant antithrombotic medication, concomitant diseases and unstable INR $[4,5]$.

Genetic variability related to the anticoagulant response to warfarin, and possibly related to the risk of bleeding, has been intensely investigated over the last years [2,6-10]. The two genes VKORC1 and CYP2C9 have been identified as the most common sources of genetic variation affecting warfarin dose requirements along with CYP4F2 [11,12]. In combination, variants in the two genes VKORC1 and CYP2C9 explain around $20-40 \%$ of the variance in dose needed to reach INR 2.0-3.0. The large genetic effects on warfarin dose requirements have enabled the development of pharmacogenetic dose prediction models and today
Niclas Eriksson*,1, Lars Wallentin', Lars Berglund', Tomas Axelsson², Stuart Connolly ${ }^{3}$, John Eikelboom ${ }^{3}$, Michael Ezekowitz ${ }^{4}$, Jonas Oldgren', Guillaume Paré $^{3}$, Paul Reilly ${ }^{5}$, Agneta Siegbahn², Ann-Christine Syvanen ${ }^{2}$, Claes Wadelius ${ }^{6}$, Salim Yusuf $^{3} \&$ Mia Wadelius ${ }^{2}$ 'Uppsala Clinical Research Center \& Department of Medical Sciences, Uppsala University, Uppsala, Sweden ${ }^{2}$ Department Medical Sciences \& Science for Life Laboratory, Uppsala University, Uppsala, Sweden

${ }^{3}$ Population Health Research Institute, Hamilton Health Sciences \& McMaster University, Hamilton, ON, Canada ${ }^{4}$ Sidney Kimmel Medical Collage at Thomas Jefferson University, Philadelphia, PA, USA

${ }^{5}$ Boehringer Ingelheim Pharma Inc., Ridgefield, CT, USA

${ }^{6}$ Department of Immunology, Genetics \& Pathology \& Science for Life Laboratory, Uppsala University, Uppsala, Sweden

*Author for correspondence: Niclas.Eriksson@ucr.uu.se

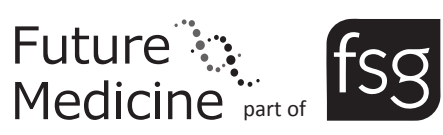


prediction models exist for maintenance dose, loading dose and dose revisions [13]. Pharmacogenetic prediction models for warfarin dose have been compared with standard care or a clinical algorithm in randomized clinical trials with varying results $[14,15]$.

Patients in the warfarin arm of the genomic substudy of the RE-LY clinical trial are included in this genomewide association study (GWAS). We hypothesized that genetic markers other than the known CYP2C9, VKORC1 and CYP4F2 might affect warfarin maintenance dose and that there might exist genetic variants affecting time in therapeutic range (TTR). We also investigated if any of the additional variables renal function, smoking, CYP4F2 or in this study identified genetic markers might improve performance of future prediction models for warfarin dosing. Furthermore, we investigated the possible clinical associations of the previously known variants rs9923231 from VKORC1, CYP2C9*2 and *3 and rs 2108622 from CYP4F2 with TTR, time below INR 2.0, time above INR 3.0 or risk of major bleeding.

\section{Materials \& methods}

RE-LY was a randomized clinical trial comparing two doses of dabigatran (110 or $150 \mathrm{mg}$ twice daily) with warfarin for stroke prevention in 18,113 patients with documented AF and at least one additional risk factor for stroke. The primary efficacy end point of the RE-LY trial was stroke or systemic embolism and the primary safety outcome was major bleeding during a mean follow-up of 2 years. The study design and results have been described previously [16,17]. In the genomic substudy of the RE-LY trial, 3076 patients consented to provide blood samples for DNA analyses. The current study focuses on 982 warfarin-treated patients with genetic samples.

Eligibility for the trial required documented AF and at least one of the following additional risk factors: first, history of previous stroke, transient ischemic attack or systemic embolism; second, ejection fraction less than 0.40 ; third, symptomatic heart failure, New York Heart Association class 2 or higher in the last 6 months; fourth, age at least 75 years or, fifth, age at least 65 years and any of diabetes mellitus, hypertension or coronary artery disease. Among the exclusion criteria were severe heart valve disorder, recent stroke, increased risk of hemorrhage, creatinine clearance less than $30 \mathrm{ml} / \mathrm{min}$ or active liver disease. Patients on vitamin $\mathrm{K}$ antagonist (VKA) treatment at the time of randomization stopped their treatment on the day of randomization and began treatment at INR below 3.0 if assigned to warfarin. The local investigator was responsible for warfarin dose adjustments required to reach and maintain an
INR of 2.0-3.0. After the initial dose titration phase, patients randomized to warfarin underwent INR testing at least once a month and measures were adopted to maximize the TTR 2.0-3.0 [17]. A dose-adjustment algorithm including an initiation nomogram and an action table that proposed dose adjustments was provided, but its use was not mandatory according to the study protocol [17].

\section{Study end points}

Warfarin maintenance dose was calculated as the mean of all doses during stable anticoagulation periods. A stable anticoagulation period was defined as a period of at least three measures of INR within 2.0-3.0. In patients where no stable anticoagulation periods were observed, the maintenance dose was calculated as the mean of all doses associated with an INR between 2.0 and 3.0. TTR 2.0-3.0, time below INR 2.0 and time above INR 3.0 for the first 3 months (TTR 3M) and TTR during the whole treatment period (TTR Total) were calculated using linear interpolation according to the Rosendaal method [18]. TTR 3M was calculated using all values regardless of treatment initiation or interruption and TTR Total was calculated excluding the first 7 days of treatment and treatment interruptions. Major bleeding was defined as a reduction in hemoglobin concentration by at least $20 \mathrm{~g} / \mathrm{l}$, transfusion of at least two units of blood or symptomatic bleeding in a crucial area or organ [16]. Creatinine clearance ( $\mathrm{CrCL}[\mathrm{ml} / \mathrm{min}])$ was calculated according to the Cockroft-Gault formula [16].

\section{Genotyping}

The 982 warfarin patients with DNA samples were genotyped using the Illumina Human610-quad DNA analysis BeadChip, which has 620,901 markers. Data management and quality control (QC) procedures were performed using PLINK [19]. In short, SNPs were excluded if the call rate was less than $98 \%$ or minor allele frequency (MAF) was less than 1\%. The 3405 SNPs that deviated from the Hardy-Weinberg equilibrium $\left(\mathrm{p}<10^{-6}\right)$ were flagged, but not excluded from analyses. Patients were excluded if their total call rate was less than $98 \%$, if self-reported sex did not match genetic sex or if the genetic relatedness to another patient was high (pi_hat from PLINK >0.2). Reported genetic coordinates were based on the NCBI human genome build 36 .

\section{Statistical analysis of genome-wide data}

In general, all genome-wide statistical analyses of all outcomes were performed assuming an additive genetic model, in other words, the genotypes for each SNP were coded 0,1 and 2 and handled as continuous 
variables. To account for the amount of multiplicity, a $\mathrm{p}$-value threshold of genome-wide significance was set at $0.05 / 554,725=9 \times 10^{-8}$ according to the Bonferroni method. To account for possible population stratification, all genome-wide analyses were adjusted for the first four genetic principal components [20]. Furthermore, genome-wide significant findings were validated in the large cluster 1 , shown in the plot of the first two principal components in Supplementary Figure 1, for consistency of regression coefficient (beta) estimates. The clusters were identified using k-means clustering (the Hartigan and Wong method with $\mathrm{k}=6$ ) on the four first genetic principal components.

GWAS of warfarin maintenance dose was performed using linear regression on the square root of warfarin dose (transformed to obtain normality). The analyses were adjusted by the nongenetic clinical variables from the International Warfarin Pharmacogenetics Consortium (IWPC) model and the full set of IWPC variables [7]. The full IWPC pharmacogenetic prediction model for warfarin maintenance dose includes the following variables: age, height, weight, race, enzyme inducer status (treatment with carbamazepine, phenytoin or rifampicin), amiodarone, VKORC1 rs9923231 and $C Y P 2 C 9 * 2 / * 3$.

TTR during the first 3 months and total TTR were analyzed using linear regression. Due to the low consistency of factors affecting TTR in the literature [21,22], selection of variables for adjustments were driven by the data. This was done as follows for each outcome. First, univariate effects on the outcomes were estimated. Variables with univariate $\mathrm{p}<0.10$ were analyzed in a multiple model and selected for inclusion for adjustment in the GWAS analyses if $p<0.10$ in the multiple model. Variables with previously known clinical effect could be added to the final adjustment variables although $p \geq 0.10$ based on judgment of beta estimates and precision. Assumptions of linear effect of continuous variables were inspected and where nonlinear effects were present, appropriate transformation was made. The variables eligible for inclusion as covariates were: age, weight $(\mathrm{kg})$, height $(\mathrm{cm})$, BMI $\left(\mathrm{kg} / \mathrm{m}^{2}\right)$, gender, systolic and diastolic blood pressure at baseline $(\mathrm{mmHg}), \mathrm{CrCl}(\mathrm{ml} / \mathrm{min})$, type of $\mathrm{AF}$, $\mathrm{CHADS}_{2}$ score [23], previous stroke, previous diabetes mellitus, previous hypertension, history of VKA use, VKA use class at entry, baseline INR, treatment with aspirin, angiotensin-II receptor antagonists, ACEinhibitors, clopidogrel, amiodarone, statins, proton pump inhibitors, H2-blockers, P-glycoprotein (P-gp) inhibitors and intake of any liver enzyme inducer (carbamazepine, phenytoin or rifampicin).

All statistical analyses on a genome-wide scale were performed using GenABEL [24].

\section{Table 1. Baseline characteristics and outcomes.}

\begin{tabular}{|c|c|}
\hline Characteristics & Outcomes \\
\hline Total number of patients & 956 \\
\hline Age (years) & $72(68-77)$ \\
\hline Gender (male) & $632(66 \%)$ \\
\hline Height $(\mathrm{cm})$ & $173(166-178)$ \\
\hline Weight (kg) & $85(75-96)$ \\
\hline BMI $\left(\mathrm{kg} / \mathrm{m}^{2}\right)$ & $28.4(25.7-32.2)$ \\
\hline Systolic blood pressure $(\mathrm{mmHg})$ & $133(120-146)$ \\
\hline Diastolic blood pressure $(\mathrm{mmHg})$ & $80(70-85)$ \\
\hline $\mathrm{CrCl}(\mathrm{ml} / \mathrm{min})$ & $73(58-90)$ \\
\hline Smoker: yes & $70(7 \%)$ \\
\hline History of VKA use & $772(81 \%)$ \\
\hline VKA naive at baseline ${ }^{\dagger}$ & $387(40 \%)$ \\
\hline Oral anticoagulation at baseline & $726(76 \%)$ \\
\hline Previous stroke & $93(10 \%)$ \\
\hline Diabetes mellitus & $189(20 \%)$ \\
\hline Hypertension & $729(76 \%)$ \\
\hline Baseline INR & $1.8(1.2-2.5)$ \\
\hline \multicolumn{2}{|l|}{ Medications at baseline } \\
\hline Aspirin & $289(30 \%)$ \\
\hline Angiotensin-II receptor antagonists & $230(24 \%)$ \\
\hline ACE inhibitors & $448(47 \%)$ \\
\hline Clopidogrel & $45(5 \%)$ \\
\hline Amiodarone & $82(9 \%)$ \\
\hline Statins & $465(49 \%)$ \\
\hline Proton pump inhibitors & $123(13 \%)$ \\
\hline H2 blockers & $39(4 \%)$ \\
\hline P-gp inhibitors & $200(21 \%)$ \\
\hline Inducer status ${ }^{\ddagger}$ & $12(1 \%)$ \\
\hline \multicolumn{2}{|l|}{$\mathrm{CHADS}_{2}$ score } \\
\hline 0 & $34(4 \%)$ \\
\hline 1 & $329(34 \%)$ \\
\hline 2 & $327(34 \%)$ \\
\hline 3 & $168(18 \%)$ \\
\hline 4 & $74(8 \%)$ \\
\hline 5 & $22(2 \%)$ \\
\hline 6 & $2(0 \%)$ \\
\hline \multicolumn{2}{|l|}{ Type of AF } \\
\hline Paroxysmal & $321(24 \%)$ \\
\hline \multicolumn{2}{|c|}{$\begin{array}{l}\text { Continuous variables are presented as median (interquartile range) and categorical variable } \\
\text { are presented as } n(\%) \text {. } \\
\text { 'Duration of previous VKA treatment } \leq 2 \text { months. } \\
\text { †Taking any of carbamazepine, phenytoin or rifampicin [7]. } \\
\text { AF: Atrial fibrillation; } C r C l: \text { Creatinine clearance; INR: International normalized ratio; } \\
\text { TTR: Time in theraputic range (2-3); VKA: Vitamin K antagonist. }\end{array}$} \\
\hline
\end{tabular}


Table 1. Baseline characteristics and outcomes (cont.).

\begin{tabular}{|c|c|}
\hline Characteristics & Outcomes \\
\hline Permanent & $344(36 \%)$ \\
\hline Persistent & $291(30 \%)$ \\
\hline \multicolumn{2}{|l|}{ Ethnicity } \\
\hline Asian & $19(2 \%)$ \\
\hline African & $7(1 \%)$ \\
\hline Other & $100(10 \%)$ \\
\hline White & $830(87 \%)$ \\
\hline Warfarin maintenance dose (mg/week) & $29.6(21.9-37.6)$ \\
\hline \multicolumn{2}{|l|}{ TTR } \\
\hline First 3 months (\%) & $61.7(42.1-81.6)$ \\
\hline Total $(\%)$ & $72.2(61.4-81.2)$ \\
\hline Stroke or systemic embolism & $24(2.5 \%)$ \\
\hline Major bleeding & $53(5.5 \%)$ \\
\hline \multicolumn{2}{|c|}{$\begin{array}{l}\text { Continuous variables are presented as median (interquartile range) and categorical variable } \\
\text { are presented as } n(\%) \text {. } \\
\text { 'Duration of previous VKA treatment } \leq 2 \text { months. } \\
\text { "Taking any of carbamazepine, phenytoin or rifampicin [7]. } \\
\text { AF: Atrial fibrillation; CrCl: Creatinine clearance; INR: International normalized ratio; } \\
\text { TTR: Time in theraputic range (2-3); VKA: Vitamin K antagonist. }\end{array}$} \\
\hline
\end{tabular}

Imputation using reference panels

To enrich for SNPs in regions with genome-wide hits, variants were imputed one megabase upstream and one megabase downstream of each hit using public available reference panels. Impute v2.2.2 was used for the imputation $[25,26]$ and SHAPEIT was used for prephasing the RE-LY data [27]. The 1000 Genomes Phase I integrated variant set (February 2012) was used as reference set for the imputations [28].

\section{Statistical analysis of phenotype \& candidate gene data on maintenance dose}

Univariate and multiple analyses of candidate variables evaluated for predictive ability of warfarin dose were performed using linear regression on the square root transformed dose. $\mathrm{R}^{2}$ values were reported on the original scale of the variable by retransforming the predicted values and calculating the squared correlation between the predicted and observed values. To reduce the effects of overfitting, the added $\mathrm{R}^{2}$ to the pharmacogenetic base model that included all the IWPC covariates, was evaluated using cross validation with 10,000 resamples of data; $70 \%$ of patients as training data set and $30 \%$ of patients as validation data set. The median and the 2.5 and 97.5 percentiles of the resulting retransformed $\mathrm{R}^{2}$ distribution were presented as point estimate and 95\% confidence interval. As $\mathrm{R}^{2}$ values can be quite abstract, we also calculated a set of more clinically intuitive measures. These included the percentage of patients predicted within $20 \%$ of the observed dose in total and in subclasses of patients with observed dose $\leq 21 \mathrm{mg} /$ week, $>21$ to $<49 \mathrm{mg} /$ week and $\geq 49 \mathrm{mg} /$ week as well as the number needed to treat
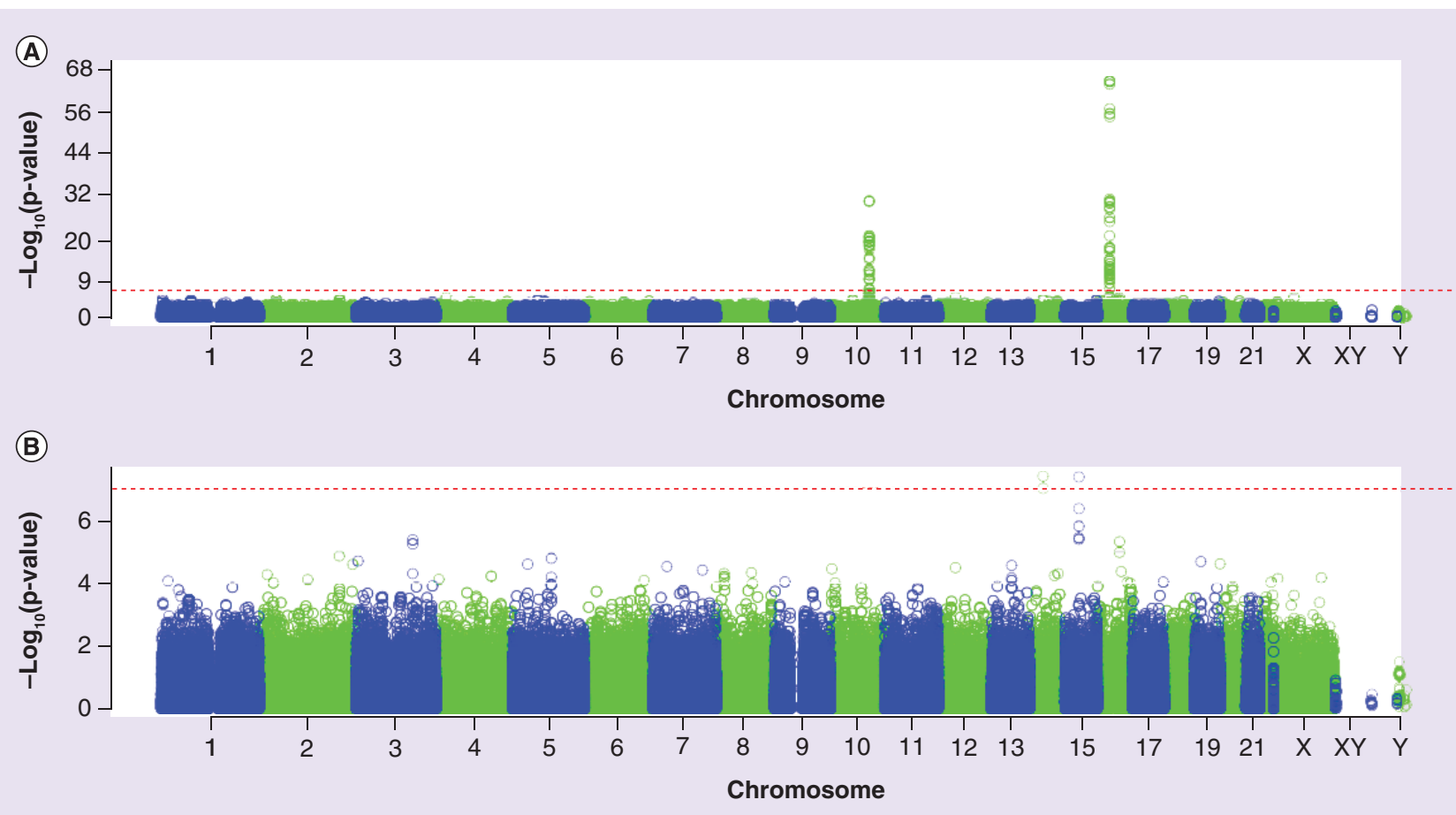

Figure 1. The analysis of warfarin maintenance dose. (A) Adjusted for clinical factors and the first four genetic principal components. (B) Adjusted for clinical factors, genetic factors (VKORC1 rs9923231 and CYP2C9*2/*3) and the first four genetic principal components. In (A \& B), the red dashed line indicates the threshold for genome-wide significance. 
Table 2. Genome-wide hits.

\begin{tabular}{|c|c|c|c|c|c|c|c|c|c|}
\hline Outcome & SNP & Chr & Pos & Gene & $\mathbf{N}$ & MAF & Beta $(95 \% \mathrm{Cl})$ & p-value & $\begin{array}{l}\text { HWE } \\
\text { p-value }\end{array}$ \\
\hline Warfarin dose & rs10871454 & 16 & 30955580 & STX4 & 951 & 37.9 & $0.82(-0.91$ to -0.72$)$ & $4.40 \times 10^{-64}$ & 0.19 \\
\hline Warfarin dose & rs4917639 & 10 & 96715525 & CYP2C9 & 951 & 19.4 & $-0.72(-0.84$ to -0.60$)$ & $8.47 \times 10^{-32}$ & 0.76 \\
\hline Warfarin dose & rs1057910 (*3) & 10 & 96731043 & CYP2C9 & 951 & 6.6 & $-0.93(-1.11$ to -0.74$)$ & $1.77 \times 10^{-22}$ & 0.30 \\
\hline $\begin{array}{l}\text { Warfarin dose } \\
\text { (adjusted }^{+} \text {) }\end{array}$ & rs2288344 & 15 & 53909639 & NEDD4 & 951 & 30.2 & $0.20(0.13-0.28)$ & $3.96 \times 10^{-8}$ & 0.76 \\
\hline $\begin{array}{l}\text { Warfarin dose } \\
\text { (adjusted }^{\dagger} \text { ) }\end{array}$ & rs17126068 & 14 & 52569647 & $D D H D 1$ & 951 & 1.4 & $-0.80(-1.09$ to -0.52$)$ & $4.14 \times 10^{-8}$ & 1.00 \\
\hline TTR in total & rs4379440 & 8 & 62628368 & $A S P H$ & 938 & 7.6 & $-6.82(-9.27$ to -4.37$)$ & $5.00 \times 10^{-8}$ & 0.25 \\
\hline
\end{tabular}

(NNT) to prevent one patient from being predicted outside $20 \%$ of the actual dose $[7,29]$. Furthermore, to graphically evaluate additional factors, we plotted the difference in the absolute residual of a base model to a new model including an additional covariate. In these graphs, the reported values of difference are on the original scale of the variable. A negative value indicates that the new prediction is worse and a positive value indicates that the new prediction is better.

Statistical analysis of candidate gene data on TTR \& major bleeding Univariate effects of VKORC1, CYP2C9 and CYP4F2 on TTR outcomes were evaluated using the non-

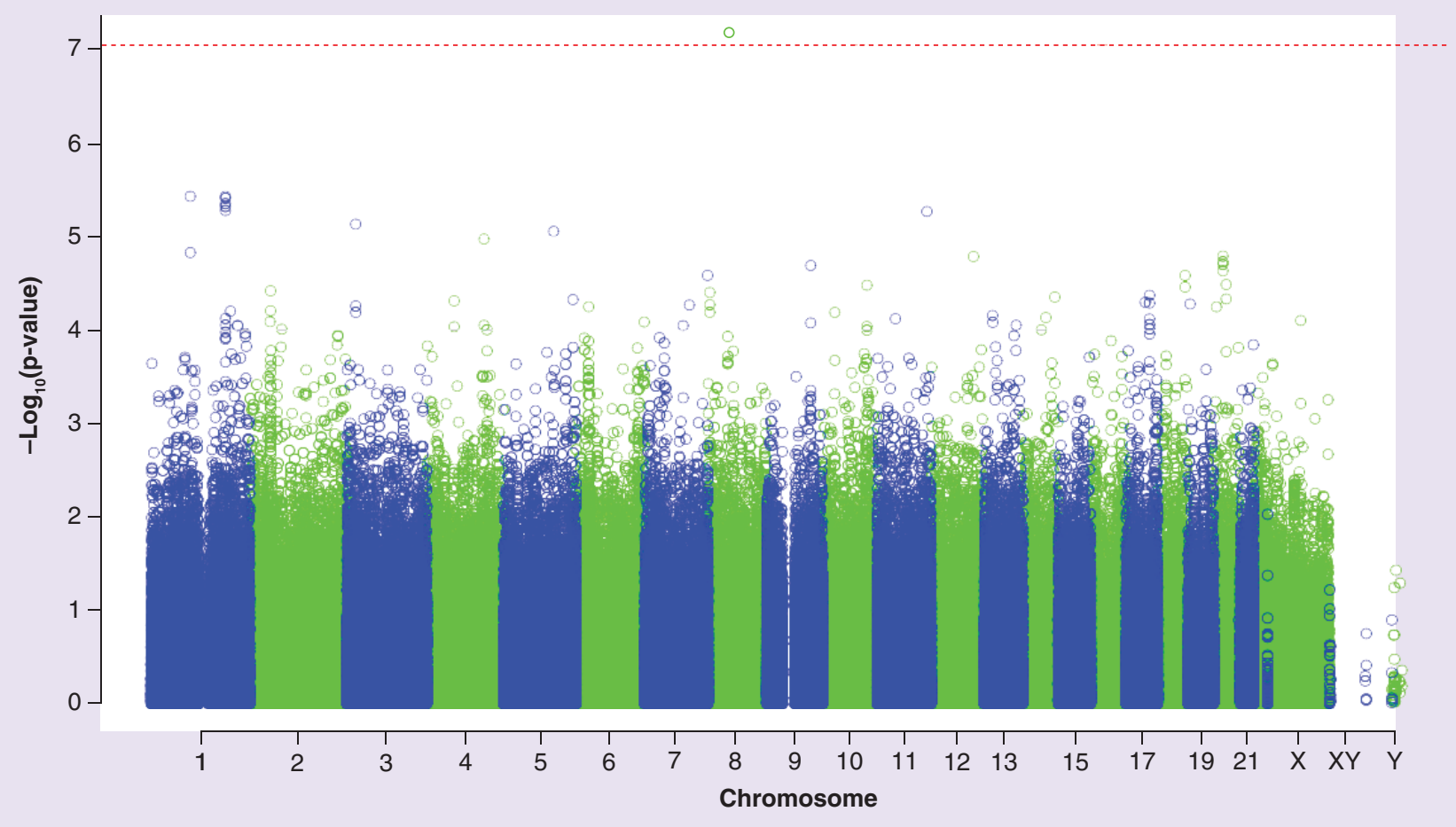

Figure 2. The analysis of TTR in total adjusted for clinical factors and the first four principal components. The red dashed line indicates the threshold for genome-wide significance. 
Table 3. Univariate and multiple effects for potential candidates for inclusion in future prediction models of warfarin dose.

\begin{tabular}{|c|c|c|c|c|c|c|}
\hline \multirow[t]{2}{*}{ Variable } & \multicolumn{3}{|c|}{ Univariate } & \multicolumn{3}{|c|}{ Multiple $^{\dagger}$} \\
\hline & $\mathbf{R}^{2}$ & p-value & Beta $(95 \% \mathrm{Cl})$ & $\begin{array}{l}\text { Added } \mathbf{R}^{2}(95 \% \mathrm{Cl}) \\
\text { to the base } \\
\text { model }^{\ddagger}\end{array}$ & p-value & beta $(95 \% \mathrm{Cl})$ \\
\hline $\begin{array}{l}\text { Base model } \\
\text { including all IWPC } \\
\text { variables }\end{array}$ & - & - & - & $51.6 \%(44.5-58.3)^{\S}$ & - & - \\
\hline $\mathrm{CrCl}(\mathrm{ml} / \mathrm{min})$ & $9.6 \%$ & $6.30 \times 10^{-23}$ & $0.013(0.011-0.016)$ & $0.4 \%(-1.5-1.1)$ & $6.51 \times 10^{-4}$ & $0.005(0.002-0.008)$ \\
\hline Smoking (yes) & $0.0 \%$ & $8.57 \times 10^{-1}$ & $-0.025(-0.300-0.250)$ & $0.0 \%(-0.7-0.1)$ & $2.79 \times 10^{-1}$ & $-0.102(-0.288-0.083)$ \\
\hline $\begin{array}{l}\text { CYP4F2 rs2108622 } \\
(\mathrm{G}>\mathrm{A})\end{array}$ & $0.8 \%$ & $1.96 \times 10^{-3}$ & $0.159(0.046-0.272)$ & $1.0 \%(-0.9-2.0)$ & $3.64 \times 10^{-6}$ & $0.178(0.103-0.253)$ \\
\hline $\begin{array}{l}\text { DDHD1 rs17126068 } \\
(\mathrm{A}>\mathrm{G})\end{array}$ & $1.2 \%$ & $2.26 \times 10^{-4}$ & $-0.827(-1.264$ to -0.389$)$ & $1.1 \%(-0.6-2.7)$ & $7.03 \times 10^{-8}$ & $\begin{array}{l}-0.809(-1.100 \text { to } \\
-0.517)\end{array}$ \\
\hline $\begin{array}{l}\text { NEDD4 rs2288344 } \\
(\mathrm{A}>\mathrm{C})\end{array}$ & $1.1 \%$ & $5.53 \times 10^{-3}$ & $0.172(0.062-0.283)$ & $1.3 \%(-0.9-2.5)$ & $4.20 \times 10^{-7}$ & $0.191(0.117-0.264)$ \\
\hline \multicolumn{7}{|c|}{$\begin{array}{l}\mathrm{R}^{2} \text { values are reported on the original scale of the variable. } \\
{ }^{\dagger} \text { After adding the variable to the base model including the variables in the IWPC model: age, weight, height, amiodarone, inducer status (any of carbamazepine, } \\
\text { phenytoin and rifampicin), ethnicity, VKORC1 rs9923231 and CYP2C9*2/*3. } \\
\text { "Calculated as the median and } 95 \% \mathrm{CI}\left(2.5 \text { percentile; } 97.5 \text { percentile) of the resulting } \mathrm{R}^{2} \text { distribution created by } 10,000 \text { cross validations ( } 70 \% \text { of data as training }\right. \\
\text { and } 30 \% \text { as validation). } \\
{ }^{5} \text { Total } \mathrm{R}^{2} \text { of the base model. }\end{array}$} \\
\hline
\end{tabular}

parametric Kruskal-Wallis test (due to the skewed distribution of time below INR 2.0 and time above INR 3.0). Major bleeding was evaluated using Fisher's exact test and hazard ratios were estimated using Coxregression. In addition to the analysis of single variants of $V K O R C 1$ and CYP2C9, a responder category was created according to Mega et al. [30] as following:

- Normal responders: VKORC1 G/G and $\left(\right.$ CYP $2 C 9^{*} 1 / * 2$ or $\left.* 1 / * 2\right)$;

- Sensitive responders: VKORC1 G/G and $\left(C Y P 2 C 9^{*} 1 / * 3\right.$ or ${ }^{*} 2 /{ }^{*} 2$ or $\left.{ }^{*} 2 / * 3\right)$ or $V K O R C 1$ $\mathrm{A} / \mathrm{G}$ and $\left(C Y P 2 C 9^{*} 1 /{ }^{*} 2\right.$ or ${ }^{*} 1 /{ }^{*} 3$ or $\left.* 2 / * 2\right)$ or VKORC1 A/A and (CYP2C9*1/*1 or * $\left.1 /{ }^{*} 2\right)$;

- Highly sensitive responders: VKORC1 G/G and $\left(C Y P 2 C 9^{*} 3 / 3\right)$ or VKORC1 A/G and $\left(C Y P 2 C 9^{*} 2 / * 3\right.$ or $\left.{ }^{*} 3 / * 3\right)$ or $V K O R C 1 \mathrm{~A} / \mathrm{A}$ and $\left(\right.$ CYP2C9* $1 /{ }^{*} 3$ or $* 2 / * 2$ or $* 2 / * 3$ or $\left.* 3 / * 3\right)$.

In the analyses of phenotype and candidate gene data, the significance level was set at 0.05 . All statistical analyses were done using $\mathrm{R}$ ( $\mathrm{R}$ Foundation for Statistical Computing, Vienna, Austria).

\section{Results}

Baseline characteristics \& outcomes

Baseline characteristics and outcomes are given in Table 1. All subsequent analyses are reported based on the 956 patients and 554,725 markers that passed QC in the warfarin treatment arm. These patients had a median follow-up of 816 days. $81 \%$ had a history of VKA use and $40 \%$ were warfarin naive at baseline (duration of previous VKA treatment $\leq 2$ months). The maintenance dose of warfarin could be calculated in 951 patients and the median value was $29.6 \mathrm{mg} /$ week. $38(4 \%)$ of the 951 patients did not achieve any stable anticoagulation period, hence the mean of all doses achieving INR 2.0-3.0 was used for these patients. Overall median TTR was $72.2 \%$ (mean: $70.1 \%$ ), whereas the median TTR in the first 3 months was 61.7\% (mean: 61.0\%). Fifty-three major bleeding events were reported corresponding to an incidence rate of $2.6 \%$ per patient year.

\section{GWAS in relation to warfarin maintenance dose}

A Manhattan plot of the GWAS results for warfarin maintenance dose, adjusted for clinical factors and principal components, is shown in Figure 1A. As expected, there were two major peaks in the areas around VKORC1 and $C Y P 2 C 9$ [12]. The top hit SNPs were in a region of high LD around VKORC1 on chromosome 16 and the SNP with the highest signal was in STX4 (rs10871454, $\left.\mathrm{p}=4.40 \times 10^{-64}\right)($ Table 2 \& Supplementary Table 1$)$. However, this SNP is in high LD $\left(r^{2}=0.994\right)$ with the third most significant SNP, rs9923231, which is the VKORC1 SNP commonly used in prediction models 
for warfarin maintenance dose $[6,7,10]$. The top hit SNP in the CYP2C9 region (rs9332220, $\mathrm{p}=5.64 \times 10^{-32}$ ) is in complete LD $\left(r^{2}=1.00\right)$ with the SNP rs 4917639 that is known to tag the ${ }^{*} 2$ and ${ }^{*} 3$ variants in CYP2C9 (Table 2 \& Supplementary Table 2) [2,10].

Figure 1B shows the results of the analysis of warfarin maintenance dose when, in addition to the first model, also adjusting for VKORC1 (rs9923231) and CYP2C9 $\left({ }^{*} 2 / * 3\right)$. Two SNPs reach genome-wide significance (Table 2 \& Supplementary Table 2), one rare SNP (MAF: $1.4 \%$ ) in the intergenic region close to DDHD1 on chromosome $14\left(\mathrm{rs} 17126068, \mathrm{p}=4.14 \times 10^{-8}\right)$ as well as one more common variant (MAF: $30.2 \%$ ) located in the intron of NEDD4 on chromosome 15 (rs2288344, $\mathrm{p}=3.96 \times 10^{-8}$ ). The DDHD1 SNP was associated with a lowering of dose per minor allele (beta estimate: $-0.80 \mathrm{mg} /$ week on square root scale); however, no homozygotes for the minor allele were present. On the contrary, the NEDD 4 SNP was associated with an increase of $0.20 \mathrm{mg} /$ week (on square root scale) per minor allele. Descriptive statistics per genotype of the two SNPs are given in Supplementary Table 3. Imputation around each top hit in the regions VKORC1, CYP2C9, DDHD1 and NEDD4 revealed no additional findings.
Subgroup analyses were performed for the two variants from NEDD 4 and DDHD1 in the largest cluster (based on PCA) to rule out the risk of confounding by population stratification. The results were similar and are presented in Supplementary Table 4.

\section{GWAS in relation to TTR}

Concerning TTR during the first 3 months, the results were adjusted for the following covariates that were significant in our study: diastolic blood pressure at baseline, previous stroke, baseline INR and the first four principal components. The results concerning total TTR were adjusted for the following factors: age, age squared (to account for nonlinear effect of age), height $(\mathrm{cm})$, AF type, $\mathrm{CHADS}_{2}$ score, previous stroke, VKA use class at entry, baseline INR, P-gp inhibitors under treatment and the first four principal components. The analysis of TTR in the first 3 months revealed no genome-wide significant signals. However, for total TTR there was a genome-wide significant hit in ASPH on chromosome 8 (Figure 2 \& Table 2), namely rs $4379440\left(\mathrm{p}=5.00 \times 10^{-8}\right)$. The SNP has a MAF of $7.6 \%$ and the effect on TTR was $-6.8 \%$ (95\% CI: -9.3 to -4.4$)$ per minor allele. Imputation in the region around rs4379440 revealed an even stronger signal

Table 4. Estimations of clinical usefulness of potential candidates for future prediction models of warfarin dose.

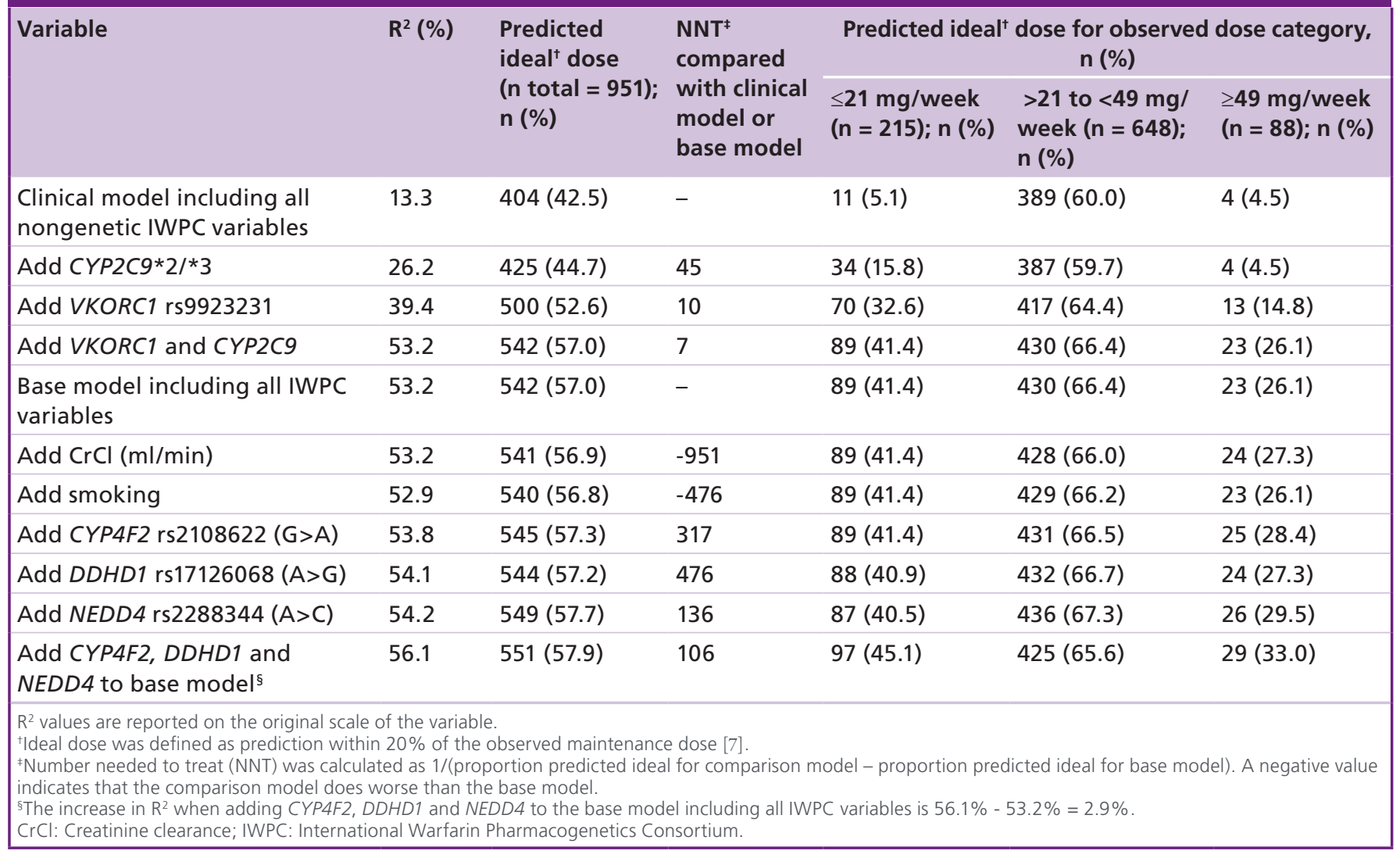




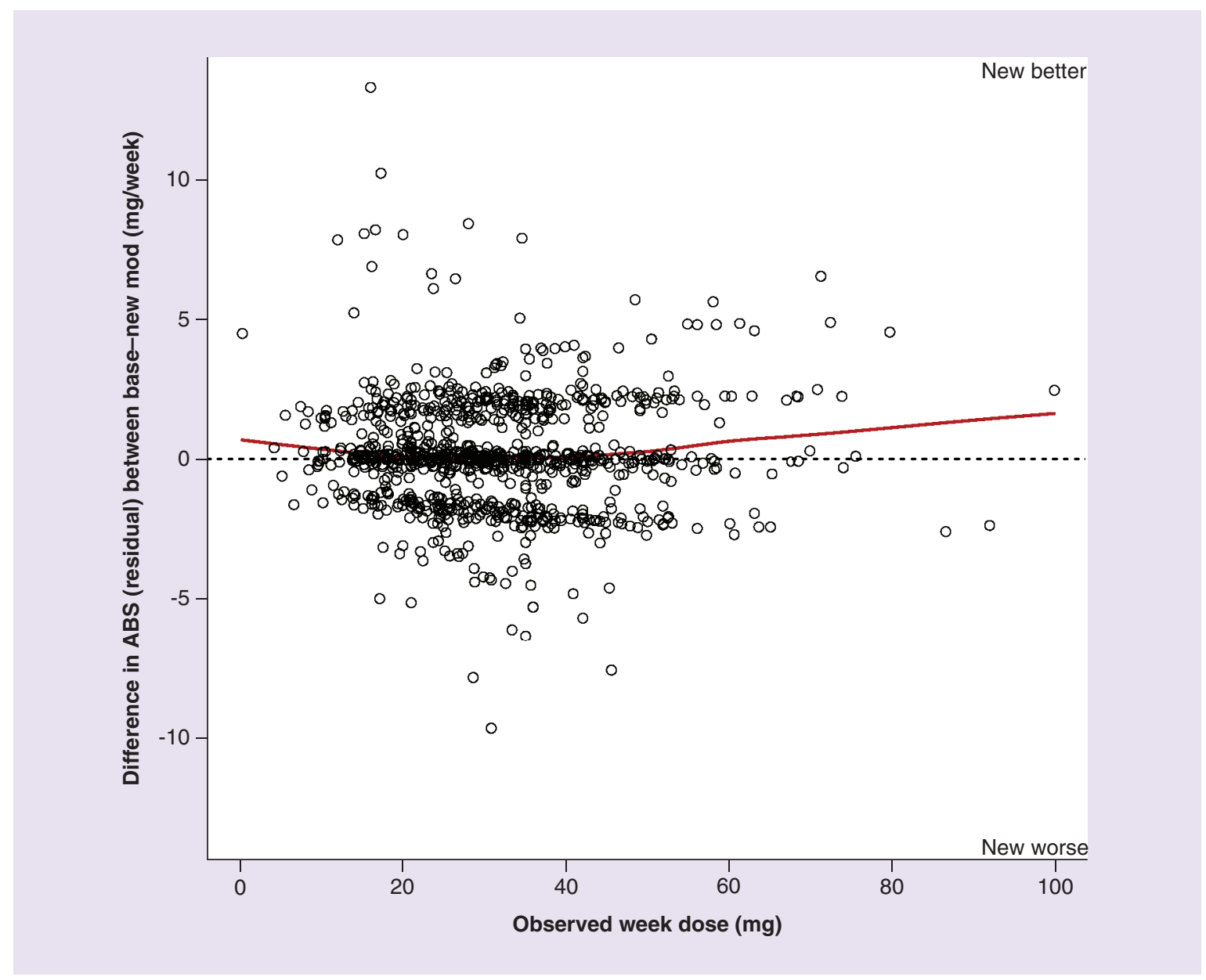

Figure 3. Added value of CYP4F2 rs2108622, DDHD1 rs17126068 and NEDD4 rs2288344 to a base prediction model including all the variables from the IWPC algorithm [7]: age, height, weight, amiodarone, inducer use, ethnicity, CYP2C9*2/*3 and VKORC1 rs9923231. Each dot illustrates a patient's difference in ABS residual between the base model and the new model. The red line is a loess smoother showing the trend in the data. ABS: Absolute.

from an imputed SNP, rs17791091 $\left(\mathrm{p}=4.13 \times 10^{-9}\right)$. It has an MAF of $6.9 \%$ and the effect on TTR was $-7.8 \%$ (95\% CI: -10.5 to -5.2$)$ per minor allele. This $\mathrm{SNP}$ is positioned in the intron region of $A S P H$ close to the typed rs4379440 SNP, which also is located in the intron, the $\mathrm{LD}\left(\mathrm{r}^{2}\right)$ between them is 0.936 .

Subgroup analysis was performed for rs 4379440 in the largest cluster (based on PCA) to rule out the risk of confounding by population stratification. The effects on total TTR were similar and are presented in Supplementary Table 4.

\section{Evaluation of additional variables for dose prediction models}

We evaluated a list of phenotypes and genotypes that could be candidates to be included in future prediction models for warfarin dosing. The variables evaluated were $\mathrm{CrCl}$, smoking and CYP4F2 rs2108622 with the addition of the novel two SNPs found in this GWAS:
DDHD1 rs17126068 and NEDD4 rs2288344. The univariate and adjusted effects on dose are shown in Table 3. $\mathrm{CrCl}$ showed a large univariate effect with an $\mathrm{R}^{2}$ of $9.6 \%$ (beta $=0.013 ; \mathrm{p}=6.30 \times 10^{-23}$ ), but much of this effect was due to the correlation of $\mathrm{CrCl}$ with age $(r=-0.60)$ and weight $(r=0.69)$. When adding $\mathrm{CrCl}$ to a base model including the variables used in the IWPC model [7], the added $\mathrm{R}^{2}$ was $0.4 \%$ but $\mathrm{CrCl}$ was still statistically significant (beta $=0.005$; $\left.p=6.51 \times 10^{-4}\right)$. As an example, the lowering of dose for patients moving from the median $\mathrm{CrCl}$ in this study of 73 to $30 \mathrm{ml} / \mathrm{min}$ is $-1.3 \mathrm{mg} /$ week $(-13.1 \%)$ for patients with a $10 \mathrm{mg} /$ week dose, $-2.3 \mathrm{mg} /$ week $(-7.7 \%)$ for patients with a $30-\mathrm{mg} /$ week dose and $-3.0 \mathrm{mg} /$ week $(-6.0 \%)$ for patients with a $50-\mathrm{mg} /$ week dose. Smoking showed no signs of being important for determination of warfarin dose (adjusted $\mathrm{p}=0.279$ ). All three SNPs evaluated (CYP4F2 rs2108622, DDHD1 rs17126068 and NEDD4 rs2288344) had statistically significant 
effects and showed univariate $\mathrm{R}^{2}$ values of approximately $1 \%$ and added roughly the same amount to the base model.

The clinical value of adding the variables to a base model including the variables used in the IWPC model are shown in Table 4 [7]. The NNT to prevent one patient from being predicted outside $20 \%$ of the actual dose was negative for $\mathrm{CrCl}$ and smoking (-951 and -476 , respectively) indicating that these factors would not improve dosing accuracy. The genetic factors CYP4F2 rs2108622, DDHD1 rs17126068 and NEDD4 rs2288344 presented with positive NNT values of 317, 476 and 136, respectively. All variables with positive NNT (i.e., the genetic factors) were used in a combined model resulting in a NNT of 106. An illustration of the performance of this model compared with the base model is shown in Figure 3. For comparison, adding CYP2C9*2/*3 and VKORC1 rs9923231 to a clinical model including all nongenetic variables from the IWPC model was also calculated (Table 4). Adding VKORC1 rs9923231 and CYP2C9*2/*3 to the clinical model gives a NNT of 7 , an illustration of the performance of this model compared with the clinical model is shown in Figure 4.

\section{Effects of VKORC1, CYP2C9 \& CYP4F2 on time}

in or out-of-range \& major bleeding

VKORC1 rs9923231, CYP2C $* 2, * 3$ and the * $2 / * 3$ composite, CYP4F2 and the responder categories according to Mega et al. [30] were evaluated against time below INR 2.0, time above INR 3.0 and TTR 2.0-3.0 for the first 3 months and for the whole treatment period. The same variables were also analyzed against major bleeding events. During the first 3 months, $V K O R C 1$ rs 9923231 was associated with time below INR 2.0 (median per genotype $\mathrm{A} / \mathrm{A}=7.5 \%$, $\mathrm{A} / \mathrm{G}=15.1 \%, \mathrm{G} / \mathrm{G}=17.2 \%$, Kruskal-Wallis $\left.\mathrm{p}=6.35 \times 10^{-4}\right)$ as well as time above INR $3.0($ median

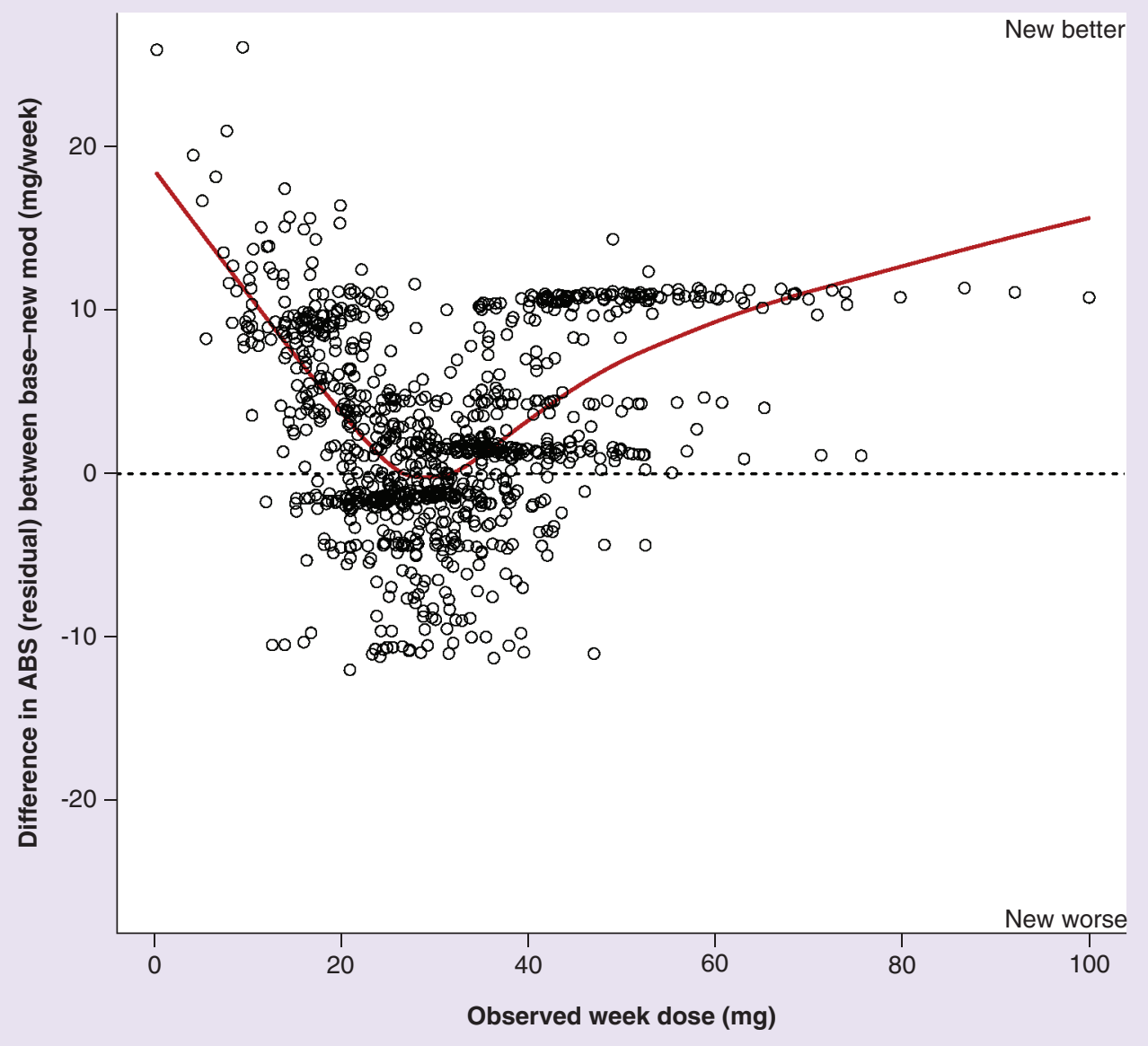

Figure 4. Added value of CYP2C9*2/*3 and VKORC1 rs9923231 to a base prediction model including the clinical variables from the IWPC algorithm [7]: age, height, weight, amiodarone, inducer use and ethnicity. Each dot illustrates a patient's difference in residual between the base model and the new model. The red line is a loess smoother showing the trend in the data.

ABS: Absolute. 

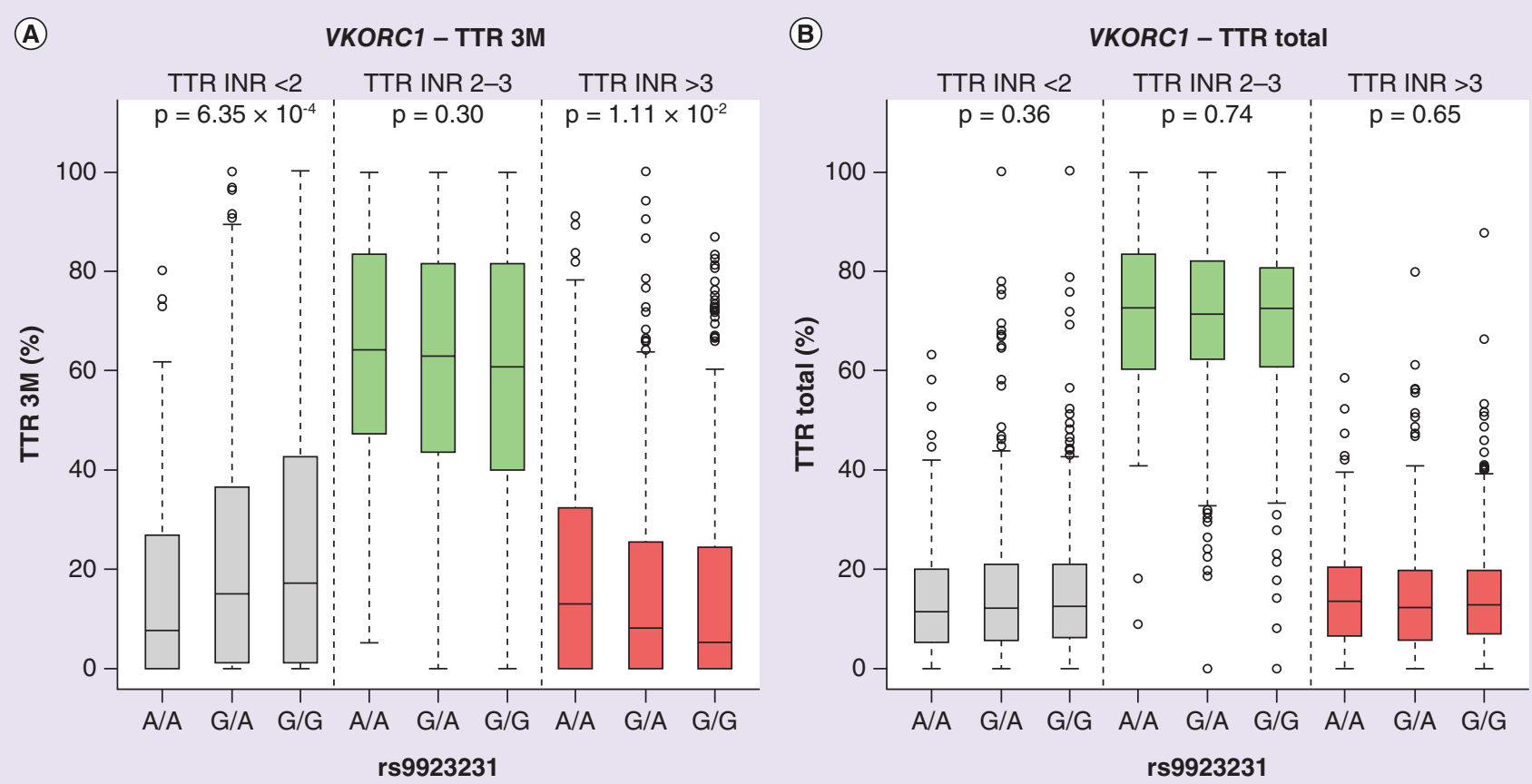

(C)

CYP2C9*3 - TTR 3M

(D)
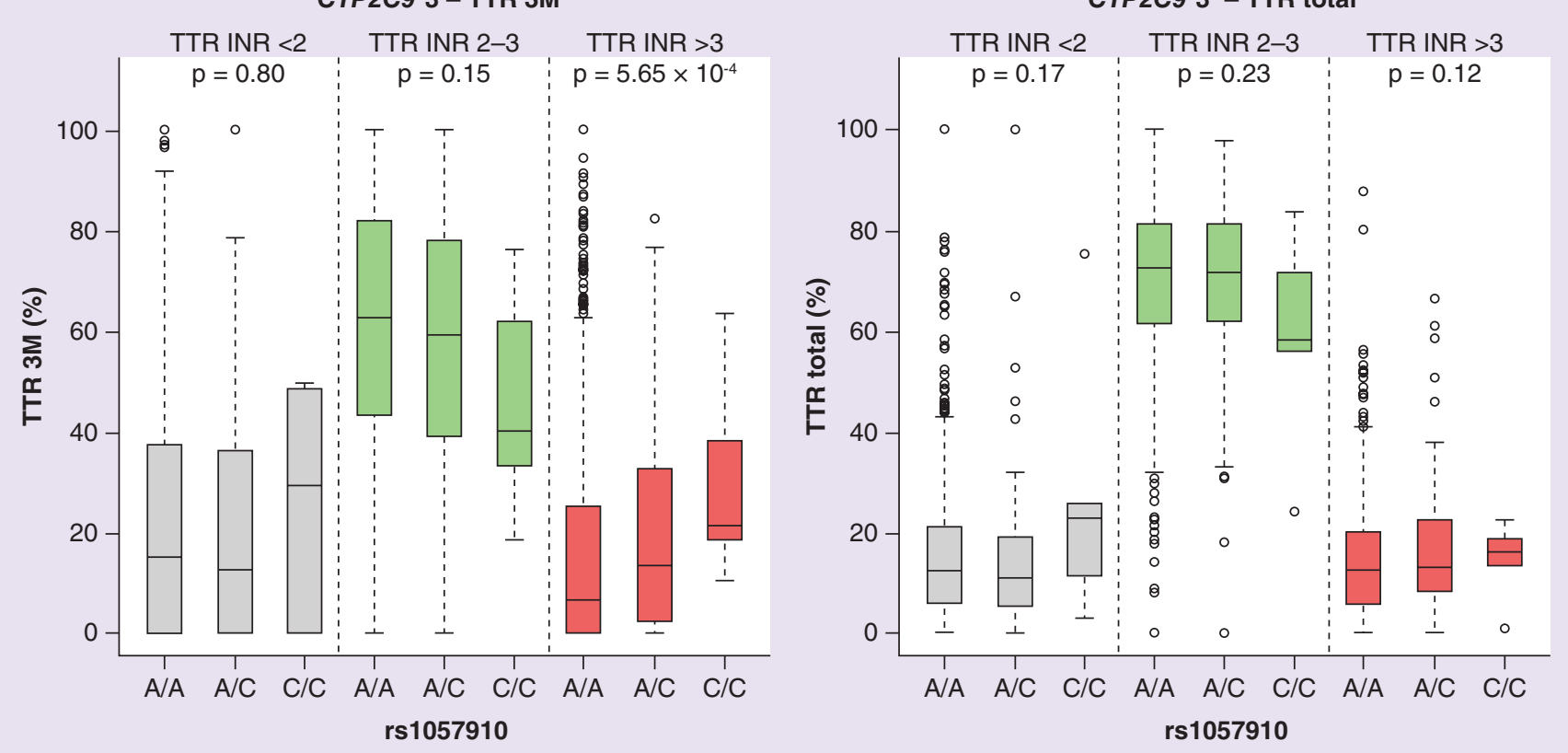

Figure 5. TTR for the first 3 months and in total by genotypes of VKORC1 rs9923231 (A \& B) and CYP2C9*3 (C \& D). The whiskers extend to the maximum value within $1.5 \times$ interquartile range, values outside this limit are indicated with circles.

INR: International normalized ratio; TTR: Time in theraputic range (as defined in the figure).

per genotype, A/A: $13.0 \%$, A/G: $8.1 \%$, G/G: $5.2 \%$; Kruskal-Wallis $\left.\mathrm{p}=1.11 \times 10^{-2}\right)$. CYP2C9*2/*3 was associated with time above INR 3.0 (Kruskal-Wallis $\left.\mathrm{p}=9.21 \times 10^{-4}\right)$. The $C Y P 2 C 9^{*} 2 / * 3$ effect was due to the effect of $C Y P 2 C 9^{*} 3$ (median per genotype, A/A: 6.5\%, A/C: $13.4 \%$, C/C: $21.3 \%$; Kruskal-Wallis $\mathrm{p}=5.65 \times 10^{-4}$ ), whereas CYP2C9*2 had no significant effect on time above target range (Kruskal-Wallis $\mathrm{p}=$ $\left.2.81 \times 10^{-1}\right)$. Furthermore, during the first 3 months, the responder categories were associated with time above INR 3.0 (median per category: normal responder $3.4 \%$, sensitive responder $12.6 \%$ and highly sensitive responder $13.3 \%$, Kruskal-Wallis $\left.\mathrm{p}=4.35 \times 10^{-5}\right)$ and time below INR 2.0 (median per category, nor- 
mal responder: $17.0 \%$, sensitive responder: $11.9 \%$ and highly sensitive responder: $12.3 \%$; KruskalWallis $\mathrm{p}=1.30 \times 10^{-2}$ ). No other time in or out-ofrange outcomes were statistically significant for either TTR during the first 3 months or in total. However, trends toward what would be expected for $C Y \mathrm{P} 2 \mathrm{C} 9^{*} 3$ could be seen for all time in or out-of-range outcomes (Figure 5). There was no significant difference between the numbers of major bleeding events for the genotypes of the analyzed markers (Table 5).

\section{Discussion}

We performed a genome-wide association study on 956 warfarin-treated patients from the RE-LY study. The major findings were two novel genes affecting warfarin maintenance dose as well as one novel gene affecting TTR.
In concordance with previous GWAS of warfarin maintenance dose on patients of mainly European descent, we found major peaks around CYP2C9 and VKORC1 [12,31]. After adjustment of CYP2C9 (*2 and *3), VKORC1 (rs9923231) and clinical covariates, we found two novel genes affecting warfarin maintenance dose. The findings were located in or close to DDHD1 (rs17126068) on chromosome 14 and NEDD4 (rs2288344) on chromosome 15. DDHD1 is a phospholipase that hydrolyzes phosphatidic acid. NEDD4 is an E3 ubiquitin-protein ligase and a receptor-potentiating factor.

The GWAS analyses of warfarin maintenance dose were followed up by investigating the effect of adding the new novel markers as well as other known variables that affect warfarin maintenance dose $(\mathrm{CrCl}$, smoking and CYP4F2 rs2108622) to a warfarin dose predic-

Table 5. Major bleeding events per genotype of VKORC1 rs9923231, CYP2C9*2, *3, the *2/*3 composite and CYP4F2 rs2108622.

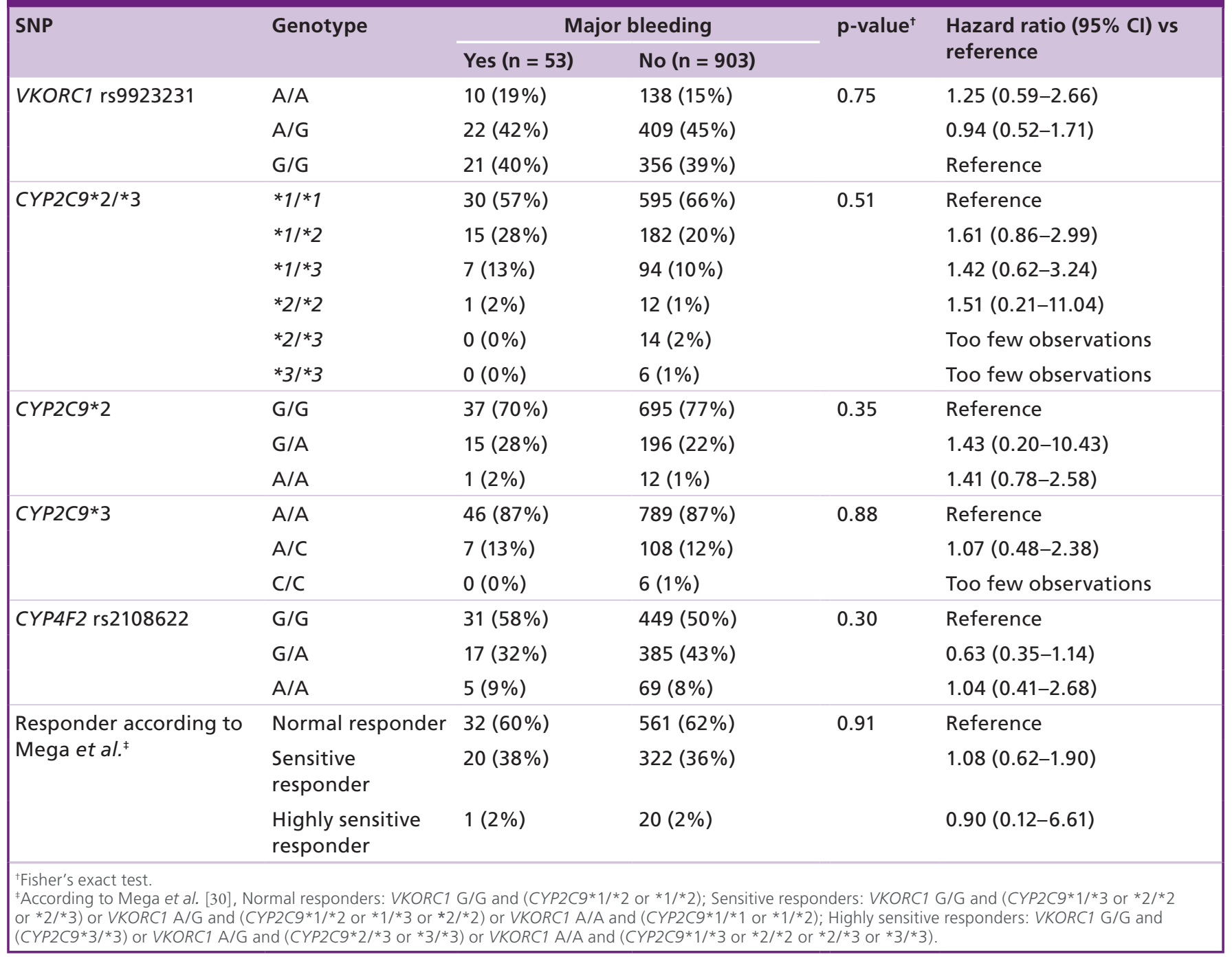


tion model including the covariates used in the IWPC prediction model [7]. The genetic variables CYP4F2 (rs2108622), DDHD1 (rs17126068) and NEDD4 (rs2288344) showed promising results with an added $\mathrm{R}^{2}$ of approximately $1 \%$ each or approximately $3 \%$ combined. However, given that adding the three genetic factors gave a NNT of 106 while doubling the number of SNPs that have to be genotyped, one can hypothesize that prospective genotyping of these additional SNPs is not cost effective in clinical practice. Although there might exist rare variants affecting warfarin sensitivity or resistance, this study indicates that for patients of European descent, the published clinical trials utilizing pharmacogenetic driven warfarin dosing were performed using appropriate genetic variants of VKORC1 and CYP2C9 [14,15].

Interestingly, our study shows no effect of smoking on warfarin maintenance dose. Smoking is thought to potentially increase warfarin metabolism, and to increase warfarin maintenance doses by approximately $10 \%$ compared with nonsmokers; however, there is also conflicting evidence showing no effect of smoking [32].

To our knowledge, this is the first study reporting GWAS results on TTR. For TTR during the whole treatment period, a genome-wide significant signal was found in $A S P H$ (rs4379440) on chromosome 8. $A S P H$ is thought to play an important role in calcium homeostasis. The gene is expressed from two promoters and undergoes extensive alternative splicing. The longest isoforms ( $\mathrm{a}$ and $\mathrm{f}$ ) include a $\mathrm{C}$-terminal domain that hydroxylates aspartic acid or asparagine residues of some proteins, including protein C, coagulation factors VII, IX, and X, and the complement factors C1R and C1S [33].

When analyzing the effect of the established warfarin-related genes VKORC1 rs9923231, CYP2C9*2/*3 and CYP4F2 rs2108622 on time in and out-of-TTR, rs9923231 was associated with both time below INR 2.0 and time above INR 3.0 during the first 3 months. Furthermore, $C Y P 2 C 9^{*} 3$ was associated with time above INR 3.0 during the first 3 months. The responder categories according to Mega et al. [30], which combines VKORC1 and CYP2C9, also had effect on INR above 3.0 and below 2.0 during the first 3 months. These results are in line with previous results on TTR measures showing that VKORC1 does have modest effect on the stability of anticoagulation in patients on warfarin, whereas the largest effect (the lowest TTR) is seen in patients homozygous for the CYP2C9*3 allele $[10,34]$. We saw no statistically significant effects on TTR during the whole treatment period. This could be due to the effect of genetic factors affecting dose which in turn affects TTR are expected to diminish over time as patient dosing is data driven and adjusted according to the INR value. Thus, TTR in the long term is expected to be more dependent on the skill of the person doing the dosing or if algorithm based dosing is used, as was encouraged in the RE-LY trial [35].

Our study did not show an effect of VKORC1 or CYP2C9 on the hard outcome major bleeding. The ENGAGE AF-TIMI 48 trial with 4833 warfarintreated patients showed an increased risk of bleeding during the first 3 months in warfarin-sensitive patients [30]. Patients were classified as sensitive if they carried the following combinations of variants: $C Y P 2 C 9^{*} 1 /{ }^{*} 3,{ }^{*} 2 /{ }^{*} 2,{ }^{*} 2 /{ }^{*} 3$ or ${ }^{*} 3 / * 3$ with any VKORC1 genotype, in addition $* 1 / * 2$ with VKORC1 A/G or VKORC1 A/A and ${ }^{*} 1 /{ }^{*} 1$ with $V K O R C 1 \mathrm{~A} / \mathrm{A}$. A conclusion from the ENGAGE trial was that nonvitamin $\mathrm{K}$ oral anticoagulants could be reserved for individuals classified as sensitive responders and therefore more likely to experience early warfarin bleeding [36]. We used the same definition of responder as in the ENGAGE AF-TIMI 48 trial but did not see any increased risk of major bleeding in the sensitive categories.

There are limitations to this study. First of all, only $40 \%$ of patients were warfarin naive at baseline and $76 \%$ of the patients were on oral anticoagulants at baseline, which affects TTR measurements. Although we could see genetic effects on TTR in the first 3 months, these results are probably underestimated due to the number of patients on oral anticoagulants at baseline. Second, a majority of the patients are white $(87 \%)$ with a low percentage of Asians (2\%) and Africans (1\%) why the results are not generalizable to these ethnic groups. Third, no patients with severe renal impairment $(\mathrm{CrCl}<30 \mathrm{ml} / \mathrm{min})$ were included in the RE-LY study creatinine clearance $<30 \mathrm{ml} / \mathrm{min}$ was an exclusion criterion. Fourth, multiple outcomes were studied that increase the chance of spurious findings and the novel findings against warfarin dose were found after adjusting for the previously known variants in VKORC1 and CYP2C9. Fifth, the genome-wide hits found in this study, have not yet been replicated in an independent cohort. And last, even though the study was fairly large with 982 warfarin-treated patients, it was underpowered with respect to the outcome major bleeding.

\section{Conclusion}

We conducted a GWAS analyzing warfarin maintenance dose and TTR in the warfarin-treated patients from the RE-LY genomics study. For both outcomes, we identified novel genome-wide significant findings. The main finding in the current study was the identification of two novel SNPs having an effect on warfarin maintenance dose. However, these SNPs provide limited incremental 
information for prediction of a patient's dose.

\section{Future perspective}

This study confirms the importance of variants within CYP2C9 and VKORC1 for the prediction of warfarin dose in patients of European descent. By adding variants from $C Y P 4 F 2, D D H D 1$ and NEDD 4 to a pharmacogenetic dose model including CYP2C9 and $V K O R C 1$, the variance in stable warfarin dose explained increased by $\sim 3 \%$. Since warfarin dosing is closely monitored by INR with subsequent dose changes if the INR is out of range, dose prediction based on CYP2C9 and VKORC1 is probably good enough in Europeans. However, in the future patients may have their genome sequenced and the results available in their medical records. In that case, even genetic variants with a limited effect on dose could be used to influence prescribing decisions.

\section{Supplementary data}

To view the supplementary data that accompany this paper please visit the journal website at: www.futuremedicine.com/ doi/full/10.2217/pgs-2016-0061
Financial \& competing interests disclosure

$\mathrm{N}$ Eriksson has received traveling grants from the Swedish Heart and Lung Foundation. M Wadelius is supported by the Swedish Research Council (Medicine 20120557 and 20140291), the Swedish Heart and Lung Foundation, the Thureus and Selander's foundations and the Clinical Research Support (ALF) at Uppsala University, Uppsala, Sweden. Genotyping was performed by the SNP\&SEQ Technology Platform in Uppsala, Sweden (www.genotyping.se) with support from the Knut and Alice Wallenberg Foundation and Uppsala University. The RE-LY study was funded by Boehringer Ingelheim Pharma Inc. N Eriksson reports institutional research grant from Boehringer Ingelheim. L Wallentin reports institutional research grants, consultancy fees, lecture fees and travel support from Bristol-Myers Squibb/Pfizer, AstraZeneca, GlaxoSmithKline and Boehringer Ingelheim, institutional research grants from Merck \& Co and Roche, and consultancy fees from Abbott. $S$ Connolly reports receiving consulting fees, lecture fees and grant support from Boehringer Ingelheim. J Eikelboom reports receiving consulting fees, lecture fees and grant support from AstraZeneca, Bayer, Boehringer-Ingelheim, Bristol-Myers Squibb, Daiichi-Sankyo, GlaxoSmithKline, Janssen, Pfizer and Sanofi-Aventis. M Ezekowitz reports receiving consulting fees, lecture fees and grant support from Boehringer Ingelheim,

\section{Executive summary}

\section{Objective}

- Warfarin treatment has some shortcomings, mainly high inter-individual variation in dose needed to reach therapeutic effect, a narrow therapeutic range and increased risk of bleeding. We hypothesized that genetic markers other than the known CYP2C9, VKORC1 and CYP4F2, might affect warfarin maintenance dose and that there might exist genetic variants affecting time in therapeutic treatment range (TTR).

\section{Materials \& methods}

- Patients in the warfarin arm of the genomic substudy of the RE-LY clinical trial are included in this genomewide association study (GWAS).

- Outcomes analyzed on a GWAS scale were: warfarin maintenance dose, TTR within 3 months and TTR in total.

- TTR, as well as time below INR 2.0 and time above INR 3.0, was evaluated within 3 months and in total were analyzed for the genetic factors rs9923231 of VKORC1,*2/*3 of CYP2C9, rs2108622 of CYP4F2 and sensitivity groups based on VKORC1 and CYP2C9. The same genetic variables were also analyzed versus major bleeding.

Results

- Novel genome-wide significant SNPs affecting warfarin dose were found in DDHD1 (rs17126068) and NEDD4 (rs2288344). Adding the new SNPs to a model including VKORC1 (rs9923231), CYP2C9 (*2/*3) and clinical factors increased $R^{2}$ by $2.9 \%$.

- A SNP in ASPH (rs4379440) on chromosome 8 was associated with TTR in total (-6.8\% per minor allele).

- During the first 3 months, VKORC1 (rs9923231) was associated with time below INR $2.0\left(p=6.35 \times 10^{-4}\right)$ and time above INR $3.0\left(p=1.11 \times 10^{-2}\right) . C Y P 2 C 9(* 2 / * 3)$ was associated with time above INR $3.0\left(p=9.21 \times 10^{-4}\right)$. Combining VKORC1 and CYP2C9 into sensitivity groups affected the same TTR measures as the individual variants. No other time in or out-of-range outcomes were statistically significant for either TTR during the first 3 months or in total.

- Major bleeding was not significantly associated with either VKORC1, CYP2C9*2/*3 or CYP4F2 genotypes as well as sensitivity groups defined by VKORC1 and CYP2C9.

\section{Conclusion}

- We identified two novel genes, DDHD1 (rs17126068) and NEDD4 (rs2288344), associated with warfarin maintenance dose and one gene, ASPH (rs4379440), associated with TTR.

- The incremental information provided by these SNPs for prediction of a patient's dose is probably limited. 
Bayer Pharmaceuticals, Pfizer, Aryx Therapeutics, Armetheon and Daiichi-Sankyo. J Oldgren reports receiving consulting fees and lecture fees from Bayer, Boehringer Ingelheim, BristolMyers Squibb and Pfizer. G Paré reports receiving lecture fees from Boehringer Ingelheim. P Reilly reports being an employee of Boehringer Ingelheim. A Siegbahn reports institutional research grants from AstraZeneca, Boehringer Ingelheim, Bristol-Myers Squibb/Pfizer and GlaxoSmithKline. S Yusuf reports receiving consulting fees, lecture fees and grant support from Boehringer Ingelheim and consulting fees from AstraZeneca, Bristol-Myers Squibb and Sanofi-Aventis. The authors have no other relevant affiliations or financial involvement with any organization or entity with a financial interest in or financial conflict with the subject matter or materials discussed in the manuscript apart from those disclosed.

\section{References}

1 Hart RG, Pearce LA, Aguilar MI. Meta-analysis: antithrombotic therapy to prevent stroke in patients who have nonvalvular atrial fibrillation. Ann. Intern. Med. 146(12), 857-867 (2007).

2 Wadelius M, Chen LY, Eriksson N et al. Association of warfarin dose with genes involved in its action and metabolism. Hum. Genet. 121(1), 23-34 (2007).

3 European Heart Rhythm Association, European Association for Cardio-Thoracic Surgery, Camm AJ et al. Guidelines for the management of atrial fibrillation: the task force for the management of atrial fibrillation of the European Society of Cardiology (ESC). Eur. Heart J. 31(19), 2369-2429 (2010).

4 Hirsh J, Fuster V, Ansell J, Halperin JL. American Heart Association/American College of Cardiology Foundation guide to warfarin therapy. J. Am. Coll. Cardiol. 41(9), 1633-1652 (2003).

5 Lip GY, Frison L, Halperin JL, Lane DA. Comparative validation of a novel risk score for predicting bleeding risk in anticoagulated patients with atrial fibrillation: the HASBLED (hypertension, abnormal renal/liver function, stroke, bleeding history or predisposition, labile inr, elderly, drugs / alcohol concomitantly) score. J. Am. Coll. Cardiol. 57(2), 173-180 (2011).

6 Gage BF, Eby C, Johnson JA et al. Use of pharmacogenetic and clinical factors to predict the therapeutic dose of warfarin. Clin. Pharmacol. Ther. 84(3), 326-331 (2008).

7 Klein TE, Altman RB, Eriksson N et al. Estimation of the warfarin dose with clinical and pharmacogenetic data. N. Engl. J. Med. 360(8), 753-764 (2009).

8 Rieder MJ, Reiner AP, Gage BF et al. Effect of VKORC1 haplotypes on transcriptional regulation and warfarin dose. N. Engl. J. Med. 352(22), 2285-2293 (2005).

9 Wadelius M, Chen LY, Downes K et al. Common VKORC1 and $G G C X$ polymorphisms associated with warfarin dose. Pharmacogenomics J. 5(4), 262-270 (2005).

10 Wadelius M, Chen LY, Lindh JD et al. The largest prospective warfarin-treated cohort supports genetic forecasting. Blood 113(4), 784-792 (2009).
No writing assistance was utilized in the production of this manuscript.

\section{Ethical conduct of research}

The authors state that they have obtained appropriate institutional review board approval or have followed the principles outlined in the Declaration of Helsinki for all human or animal experimental investigations. In addition, for investigations involving human subjects, informed consent has been obtained from the participants involved.

\section{Open access}

This work is licensed under the Attribution-NonCommercialNoDerivatives 4.0 Unported License. To view a copy of this license, visit http://creativecommons.org/licenses/by-nc-nd/4.0/

11 Caldwell MD, Awad T, Johnson JA et al. CYP4F2 genetic variant alters required warfarin dose. Blood 111(8), 4106-4112 (2008).

12 Takeuchi F, Mcginnis R, Bourgeois S et al. A genomewide association study confirms VKORC1, CYP2C9, and CYP4F2 as principal genetic determinants of warfarin dose. PLoS Genet. 5(3), e1000433 (2009).

13 Eriksson N, Wadelius M. Prediction of warfarin dose: why, when and how? Pharmacogenomics 13(4), 429-440 (2012).

14 Kimmel SE, French B, Kasner SE et al. A pharmacogenetic versus a clinical algorithm for warfarin dosing. N. Engl. J. Med. 369(24), 2283-2293 (2013).

15 Pirmohamed M, Burnside G, Eriksson N et al. A randomized trial of genotype-guided dosing of warfarin. N. Engl. J. Med. 369(24), 2294-2303 (2013).

16 Connolly SJ, Ezekowitz MD, Yusuf S et al. Dabigatran versus warfarin in patients with atrial fibrillation. N. Engl. J. Med. 361(12), 1139-1151 (2009).

17 Ezekowitz MD, Connolly S, Parekh A et al. Rationale and design of RE-LY: randomized evaluation of longterm anticoagulant therapy, warfarin, compared with dabigatran. Am. Heart J. 157(5), 805-810, 810e801-802 (2009).

18 Rosendaal FR, Cannegieter SC, Van Der Meer FJ, Briet E. A method to determine the optimal intensity of oral anticoagulant therapy. Thromb. Haemost. 69(3), 236-239 (1993).

19 Purcell S, Neale B, Todd-Brown K et al. PLINK: a tool set for whole-genome association and population-based linkage analyses. Am. J. Hum. Genet. 81(3), 559-575 (2007).

20 Price AL, Patterson NJ, Plenge RM, Weinblatt ME, Shadick NA, Reich D. Principal components analysis corrects for stratification in genome-wide association studies. Nat. Genet. 38(8), 904-909 (2006).

21 Pokorney SD, Simon DN, Thomas L et al. Patients' time in therapeutic range on warfarin among US patients with atrial fibrillation: Results from ORBIT-AF registry. Am. Heart J. 170(1), 141-148, 148e141 (2015).

22 Apostolakis S, Sullivan RM, Olshansky B, Lip GY. Factors affecting quality of anticoagulation control among patients 
with atrial fibrillation on warfarin: the SAMe-TT(2)R(2) score. Chest 144(5), 1555-1563 (2013).

Gage BF, Waterman AD, Shannon W, Boechler M, Rich MW, Radford MJ. Validation of clinical classification schemes for predicting stroke: results from the National Registry of Atrial Fibrillation. JAMA 285(22), 2864-2870 (2001).

24 Aulchenko YS, Ripke S, Isaacs A, Van Duijn CM. GenABEL: an R library for genome-wide association analysis. Bioinformatics 23(10), 1294-1296 (2007).

25 Howie B, Marchini J, Stephens M. Genotype imputation with thousands of genomes. G3 1(6), 457-470 (2011). Howie BN, Donnelly P, Marchini J. A flexible and accurate genotype imputation method for the next generation of genome-wide association studies. PLoS Genet. 5(6), e1000529 (2009).

Delaneau O, Marchini J, Zagury JF. A linear complexity phasing method for thousands of genomes. Nat. Methods 9(2), 179-181 (2012).

28 Genomes Project C. A map of human genome variation from population-scale sequencing. Nature 467(7319), 1061-1073 (2010).

29 Cook RJ, Sackett DL. The number needed to treat: a clinically useful measure of treatment effect. BMJ 310(6977), 452-454 (1995).

30

Mega JL, Walker JR, Ruff CT et al. Genetics and the clinical response to warfarin and edoxaban: findings from the randomised, double-blind ENGAGE AF-TIMI 48 trial. Lancet 385 (9984), 2280-2287 (2015).

31 Cooper GM, Johnson JA, Langaee TY et al. A genome-wide scan for common genetic variants with a large influence on warfarin maintenance dose. Blood 112(4), 1022-1027 (2008).

32 Nathisuwan S, Dilokthornsakul P, Chaiyakunapruk N, Morarai T, Yodting T, Piriyachananusorn N. Assessing evidence of interaction between smoking and warfarin: a systematic review and meta-analysis. Chest 139(5), 1130-1139 (2011).

33 Genecards. Version 3 (2012). www.genecards.org

34 Skov J, Bladbjerg EM, Leppin A, Jespersen J. The influence of VKORC1 and CYP2C9 gene sequence variants on the stability of maintenance phase warfarin treatment. Thrombosis Res. 131(2), 125-129 (2013).

35 Van Spall HG, Wallentin L, Yusuf S et al. Variation in warfarin dose adjustment practice is responsible for differences in the quality of anticoagulation control between centers and countries: an analysis of patients receiving warfarin in the randomized evaluation of long-term anticoagulation therapy (RE-LY) trial. Circulation 126(19), 2309-2316 (2012).

36 Wu AH. Pharmacogenomic testing and response to warfarin. Lancet 385(9984), 2231-2232 (2015). 